\title{
FISH IN NUTRITION
}

$\mathrm{T}$ HE Fisheries Division of the U.N. Food and Agriculture Organization, in collaboration with the Divisions of Nutrition and of Animal Production and Health, were responsible for organizing a conference which, at the invitation of the Government of the United States, and with generous financial assistance from the Division of General Medical Sciences through the agency of the National Academy of Sciences, was held in the new conference auditorium of the Department of State, Washington, D.C., during September 19-27. Various North American commercial fish organizations also combined to make the gathering a success.

The conference, which was attended by more than three hundred official participants and various experts and industrialists from more than thirty countries, was opened by Dr. D. B. Finn, the director of the Fisheries Division, as representative of the DirectorGeneral, after an address of welcome by the Hon. Stewart L. Udall, Secretary of the Interior. There was also a message of greetings from President Kennedy.

The chairman of the conference was Mr. Donald L. McKernan, director of the Bureau of Commercial Fisheries of the Fish and Wildlife Service of the U.S. Department of the Interior, and five main topics were discussed, each under a distinguished chairman, with a rapporteur and secretary, covering exhaustively the various biological, chemical, technological, nutritional and economic aspects of fish and fish products. For each topic a number of review papers, thirty-four in all, had been invited from well-known authorities, supplemented by thirty-five selected original short research papers. These were all circulated beforehand, the latter as abstracts only, and contributors briefly introduced their papers. The edited proceedings, including the various recommendations and conclusions, are to be published by Arthur $J$. Heighway Publications, Ltd., 110 Fleet Street, London, by arrangement with the Food and Agriculture Organ. ization, next year.

As it is impossible in the course of a short article to cover adequately such a broad and detailed agenda, a personal selection has had to be made of the various important issues that were discussed by the numerous experts present.

\section{Productivity of the Seas}

There was a clash of opinion among the marine biologists on the maximum harvest that could be expected from the seas. Some took the conservative view that knowing the quantity of solar energy that can be fixed by marine plants and making certain assumptions as to the number and efficiency of the conversion steps in the food chain, one cannot hope for much more than double, or at most treble, the present catch of slightly less than thirty million tons of marine fin fishes per annum. Others pointed out that landings from the oceans have already nearly doubled in the past ten years, and thought that there was reason for believing that, even using present methods of fishing, five or even ten times the present yield could be achieved and sustained.

At present commercial fishing operations are largely determined by market considerations. Many edible species, such as sharks, are often not brought home even when caught. A two million ton per annum fishery of anchovies used for fish meal has sprung up off the coast of Peru in less than a decade. Some American biologists believe that a similar potential exists off the coast of California, and that there are also untapped resources of saury, which would be despised as a food fish in the United States, although since the War it has been canned on a large scale in Japan. Improved methods of preventing decomposition, such as freezing at sea, is enabling Russian and Japanese ships, for example, to exploit fishing grounds all over the world.

Again, greatly improved methods of fishing can be envisaged. In spite of much effort on the part of the Food and Agriculture Organization and Governments, there is still a several hundred-fold difference between the highest and lowest productivity per fisherman. The suggestion was revived of a planned ploughing of the sea through the convectional effect of nuclear reactors, by means of which nutrient-rich ocean depths could be brought into the life-cycle of the upper layers. Finally, also looking well into the future, there is the prospect of fish farming on a scale as yet unimaginable, perhaps involving the intelligent utilization of the organic material at present prodigally wasted in sewage.

However, these distant vistas do not dispose of the fact that here and now in certain more easily accessible areas there is a decided falling off in yield due to uncontrolled fishing, with uneconomic results. The future yield in such cases is not determined only by Nature, but depends in large messure on the decisions of man himself. Man acts not only as a predator and disturber, but also as an intervener in natural systems, so that the fish stock of the future, in the words of Dr. G. L. Kesteven (Cronulla, New South Wales), "is likely to be so much more or less than it is now, as man makes it to be".

It therefore seems that, although there is no justification for pessimism, more work will be needed before the basis exists for even an approximate estimate of the potential yield of the oceans.

\section{Unequal Distribution of Fish Supplies}

Added to the uneven development of the present world fish catch is the inequality of its distribution. In this respect there is a general lack of realization of the implications of the tremendous gap that exists between the 'have' and 'have-not' nations.

Although the world dietary deficit in calories is relatively slight, so that probably relatively little actual starvation occurs, there is a general protein under-nourishment over much of the globe which greater consumption of fish could do much to remedy. Even where national statistics which are reliable indicate adequate average diets, deficiencies are known to exist in special regional or socio-economic groups. Children in the age group 1-4 years have special protein needs but often do not receive a proper share of the right foods. Kwashiorkor and marasmus are protein-deficiency conditions of infancy which cause many fatalities, particularly in Africa and South America. Women frequently pregnant and lactating equally require high animal protein intake, but all too often men get priority. Protein 
under-nourishment, even where not fatal, is responsible for untold misery, debility, disease, and retarded growth and development.

Although fish accounts for only about 12 per cent of the total animal protein available, it nourishes far more than this percentage of the world population. For more than 1,000 million people it constitutes the chief source of animal protein. Milk and meat products, although bulking much larger, feed far fewer millions. Fish is the protein of the poor, nationally and globally.

Over North America and most of Western Europe the consumption of other animal products is so much greater than that of fish that the latter could prac. tically disappear altogether from the diet without being missed. However, fish is equally nourishing for farm animals, the requirements of which have received much closer examination than those of human beings. The high and increasing output of meat products in the West is facilitated by converting about 5 million tons of edible fish annually into feeding meal for animals. Only a small proportion of this fish meal comes from recovery of industrial waste. The bulk is from whole, edible fish caught entirely for reduction, much of it in Africa and South America. 95 per cent of this trade goes to produce milk, bacon and eggs in the countries least requiring extra nutrition. For example, one third of the broiler production in the United States can be attributed to the sea.

One of the topics which received greatest attention at the conference was the part that the polyunsaturated fatty acids of fish oil could play in the prevention of obesity and coronary and cerebral thrombosis, associated with excessive meat consumption, which are now among the major killers in the 'overdeveloped' nations (as they were termed). It is a grim irony that a contributory factor to such 'overnourishment' (itself a special form of malnutrition) is the fish protein concentrate drawn from the very continents where protein under-nourishment is so rife.

But quantities that are essentially only of marginal interest to the West represent the difference between health and disease for many millions of people on the verge of starvation. Thus, if the enormous fish production of Peru, at present exported as fish meal, were consumed in South America instead, it could raise the nutritional status of that continent to the level of that of Italy.

The inequitable distribution of fish protein resources is further flaunted in the 300,000 tons of raw fish used yearly to produce fur on the mink farms of the United States and Scandinavia for a form of apparel used not so much for the warmth as the adornment of the wealthy. To quote the report issued at the end of the conference: "It is clear that 400 million people cannot continue to get the overwhelming part of the world's animal protein, while 2,500 millions are neglected and deprived of this essential nutrient". The situation is made even more acute by the expected doubling of the world's population to 6,000 millions in the next 40-50 years.

\section{Utilization of Fish}

Great disparities also emerged in considering the efficiency of utilization of fish as food for man and beast.

There was a general consensus of opinion that fish is a first-class food, rich in high-quality protein, valuable lipids and most of the fat and water. soluble vitamins and minerals. However, there are appreciable losses of nutrient in handling, processing and storage which, in extreme cases, can amount to a sheer wastage of as much as three-quarters of the substance of the fish before it is consumed. Wastage occurs in trimming raw fish, by which much of the edible flesh is left on the bone, to the benefit of fish meal again. Protein and water-soluble vitamins escape during salting, and both can suffer as much as 50 per cent loss of quality during severe drying processes. Over much of the world insects cause further loss, as much as 50 per cent being reported from Nigeria.

Furthermore, there is, even in well-developed countries, the imponderable consideration of the effect on fish consumption of loss of palatability on account of chronically careless handling of a very perishable commodity between catching and consumption.

Although there is much more that could be found out by further research, it is not lack of knowledge that is holding up technical advance so much as the lack of application of established knowledge and experience. In many cases the formulation and adoption of suitable standards of processing the product are seen as a means of providing the impetus for technical improvements.

There was a difference of opinion about the toxicity of oxidized fish oils, attributed to the extreme reactivity of hydroperoxides. Such oxidation, associated with many traditionally cured products, is also partly responsible for their characteristic flavour, which is often greatly relished in a cereal diet in circumstances where fish is regarded more as a condiment than as a source of protein.

Refrigeration and canning, which are serviceable stock methods of preservation under a wide variety of conditions, result in little or no loss nutritionally.

There did not seem to be much hope that any of the newer methods of preservation, however satisfactory nutritionally, could be expected to assume such importance that proper care and control over established processes would soon be unnecessary. Vacuum freeze-drying of fish seemed unlikely to compete in quality with freezing in the West, or in cheapness with the traditional methods used elsewhere. The possibilities of sterilization by radiation, too, seem to have been greatly over-rated. On the other hand, the recent development of a large Japanese industry for manufacture of fish sausage was noted with interest, and thought to be a means of extending the outlet for fish in many other areas. Consideration would, however, have to be given to the advisability of encouraging the use of the chemical preservatives permitted in Japan.

Much discussion centred around the possibility of producing a tasteless fish flour that could be introduced particularly into the diets of young children in needy areas. The technical difficulties and achievements to date were reviewed and standards proposed for products of acceptable quality and nutritive properties. While some saw in fish floux "the basic fishery product of the future", others felt that much more could be done here and now to improve nutrition by means of the application of knowledge and experience already available for types of fishery product known to be generally acceptable.

\section{Economic and Educational Problems}

Without denying the need for immediate emergency schemes for using fish as nourishment, other animals are not necessarily competitors with man for the fish 
supplies. A good case can be made out for the use of fish for animal feeding as part of a planned protein economy, although at present this is of more interest to the West than to the rest of the world. Much vegetable protein, in the form of grass, for example, is made available to us because cattle diets are supplemented with a small amount of fish meal. Although there is a loss of energy at each step in the food-cycle, protein may be converted with 50 per cent efficiency in ideal circumstances. Essential amino-acids such as lysine and methionine may be recovered at efficiency-levels up to 70 per cent in animal products such as hen's eggs. Ruminants, particularly, can make better use of fish products regarded as of low quality for other purposes.

However, it was admitted that animal feeding is a very opportunist operation, which makes use of whatever products and by-products are available at suitable prices. If the fish at present used for fish meal were to be upgraded to, say, fish flour, for human use, the industry would be forced once again to look for alternative sources of supply and would have to rely on industrial fish waste and such feeds as soya bean meal supplemented with synthetic amino-acids, although at somewhat higher cost.

In the world of commerce it is more profitable to make fish meal or raise mink than it is to make and distribute food for children of low-income groups. However, there are circumstances in which nations cannot afford to count the cost, and a concerted attack on freeing the world from hunger is surely a worthy cause. The Food and Agrieulture Organiza- tion has, in fact, initiated such a campaign which it is the duty of the more fortunate nations to support to their utmost. However, even if economics were over-ridden in some such manner, there are techno. logical and educational problems to tackle in getting fish consumed where it is needed. It is true that this is only one aspect of accelerating a general expansion in production and standard of living in underdeveloped countries. But more organized technical assistance needs to be given before many countries are in a position fully to help themselves. The Organization needs further support in making their self-help more effective. Training of personnel at all levels should have greater priority. Fishermen and others have to be taught to use better methods of catching and preservation. Consumers need education in the development of better dietary habits. Technical personnel, research workers and administrators all need training before programmes of fisheries expansion can be implemented.

Obviously this cannot be done overnight. However, it was felt by many at the conference that more effort should be put into education by providing expanded facilities for technicians to be trained to understand and utilize improved methods based on present knowledge and experience.

Finally, there was considerable support for the thesis that, although admitting that much of what is already known is not being made use of, increased support for fundamental research is essential for the most efficient utilization of fish in the future.

\section{L. Cutrina}

\section{THE INTERGOVERNMENTAL OCEANOGRAPHIC COMMISSION}

\begin{abstract}
$\mathrm{T}$ HE oceans, which cover some 70 per cent of the surface of the Earth, are perhaps one of the greatest fields for scientific investigation. They contain unlimited areas of study in practically every scientific discipline and yet, measured with the yardstick of our knowledge of the Earth and the atmosphere, it must be admitted that we have to learn much more about the sea before we can hope to understand its vagaries and make full use of its resources.

We know enough about it to appreciate the complexity and vastness of the problems which confront us, and there can be no doubt that many of them can only be solved when scientists co-operate on an international scale. Although one is apprehensive in condoning the establishment of more international organizations labelled with forbidding combinations of the alphabet, there is no doubt that the establishment of the Intergovernmental Oceanographic Commission (I.O.C.), which held its first meeting in Paris during October 19-27, fulfils a long-felt need and promises better co-ordination in the future for marine science.

International organizations dealing with the science of the sea have existed for many years, but they have been either of a regional nature or confined to a limited scientific field. In 1957 the International Council of Scientific Unions foresaw the necessity for a wider scale of co-ordination of activity, both geographically and disciplinary, and it established a Special Committee on Oceanic Research (S.C.O.R.) to consider such problems. The activities of the Committee are, however, primarily scientific, and
\end{abstract}

although, as one of its projects, it has initiated an international expedition to the Indian Ocean, it still remains a non-governmental organization solely dependent on co-operation with national academies or similar scientific organizations.

The Intergovernmental Oceanographic Commission, on the other hand, now makes possible a direct approach to participating governments and forms a very necessary link where projects involving considerable expenditure are contemplated. At its first meeting, Dr. Anton Brunn, of Denmark, a leading biological oceanographer, was elected chairman. Dr. William M. Cameron, director of oceanographic research for the Canadian Department of Mines and Technical Surveys, and Vice-Admiral V. A. Tchekourov, head of the Hydrographic Service at Leningrad, were elected as vice-chairmen. The Commission appointed as its secretary Dr. Warren Wooster, director of the Unesco Office of Oceanography, which will act as secretariat.

The initial task of the new body was to define its own responsibilities and the manner in which it would function, particularly in relation to existing organizations. The decisions reached show that it is prepared not only to receive the advice of existing inter-governmental and non-governmental organizations which at present advise Unesco on oceanographical matters, but also the hope was expressed that the Food and Agriculture Organization, the World Meteorological Organization and other specialized agencies of the United Nations would co-operate actively with the secretariat of the Commission. 